\title{
Sensitivity Towards Sociocultural Plagiarism in the Context of Varied Discipline among College Students
}

\author{
Lillian C. Calicdan1, Rhyan Mike R. Bacaro², Dennis C. Ramo ${ }^{3}$, \\ Rodrigo Jr. C. Licayan ${ }^{*}$ ( ${ }^{\text {https: }} / /$ orcid.org/0000-0002-9022-2314, \\ 1,2,3,4Monkayo College of Arts, Sciences and Technology, Philippines \\ *e-mail: rodrigolicayanjr.moncast@gmail.com
}

\begin{tabular}{l}
\multicolumn{1}{c}{ Article Information } \\
\hline Received: December 29, 2020 \\
Revised: February 02, 2021 \\
Accepted: February 15, 2021 \\
Online: May 30, 2021
\end{tabular}

Keywords
Sociocultural plagiarism quantitative research, discipline, local college, Philippines

\begin{abstract}
Socio-cultural plagiarism provides an understanding of the social values and attitudes among students in academic writing. Based on the rules and regulations of any academic institution, adequate awareness of different forms of plagiarism, citation techniques, paraphrasing, and other instances of copyright infringement should be tailored to any type of violation against conduct and discipline, particularly in cheating. A descriptive-comparative approach uses this study to measure the level of sensitivity among students towards socio-cultural plagiarism in terms of awareness, attitude, socio-cultural beliefs, and perception. Applying Slovin's formula, the respondents were identified using a simple random sampling technique. The results revealed that the level of sensitivity among students towards socio-cultural plagiarism is low. It is also revealed that there is no significant difference in the level of sensitivity among students towards socio-cultural plagiarism when respondents are grouped according to discipline. Therefore, as the basis for an intervention program, ethical standards of writing and the tools or technology to detect plagiarized output of the students are crucial elements towards the institution's academic standards.
\end{abstract}

\section{INTRODUCTION}

In recent years, the advent of technology and online materials provided a normative belief that information can be accessed directly and used for academic compliance by merely copying it. Thus, investigating the student's understanding of plagiarism is critical in developing a reputable academic community. With the undeniable increase in the rate of committing plagiarism and its adverse effects on the academic standards, such as damaging the credibility of higher education systems (Altbach, 2004) and diminishing the esteem of science in the mind of the general public, it provoked the educational communities around the world to pay more efforts to find the contributing factors as well as solutions to this problem (Oghabi, Pourdana, \& Ghaemi, 2020). According to PR Newswire (2013), the three common types of plagiarism and attribution issues are paraphrasing, repetitive research, and secondary source plagiarism. Other serious problems are complete plagiarism, verbatim plagiarism, and unethical collaboration.

In the global context focusing on university policies in Australia, Canada, USA, England, New Zealand, and China, the issue of plagiarism included graded levels of plagiarism, copying words, and the intentional use of other's words and works (Sutherland-Smith, 2008). Although defining plagiarism is stealing, through copy-and-paste, words, texts, or someone's ideas and claiming it as an own statement 
without proper acknowledgments of the source, it has been embraced by some scholars and students to review the academic policies about it(Park, 2003; Yeo, 2007). For example, in an Australian university, Yeo (2007) examined undergraduate science and engineering student's understanding of the concept of plagiarism and found that the students considered copying assignments and using the cut-and-paste strategy as severe forms of plagiarism. Generally, all the factors are critical contributors to the act of plagiarism, but external factors (such as peer behavior and parental pressure) are associated with personal characteristics (such as students' laziness and poor time management). Furthermore, institutional factors (such as unclear policy regarding academic misconduct) are associated with academic factors (such as poor writing skills). Moreover, personal, technological, and academic factors directly correlate with student plagiarism (Husain, Al-shaibani, Mahfoodh \& Ali, 2017).

In the Philippines, there are no national guidelines on dealing with plagiarism for academic publishing. Besides being little-discussed locally as a policy matter by academic institutions, plagiarism in the Philippines in any context is still vastly understudied. It holds the current work focusing on students' plagiarism, tackling pedagogical interventions, or plagiarism concerning legal issues. Studies discussing scholarly publishing in the Philippines tend to focus on the factors constraining publishers from matching their Western counterparts' quality and quantity of output, sustainability concerns, and other publishing challenges only. The University of the Philippines has reported faculty members and students committing plagiarism. Some of the identified cases were related to a rejected manuscript, and the publisher filed an official complaint with higher authorities. There are also instances that the chapter was rejected; copies of the introduction were removed from the printed copies of the book and replaced with a new introduction from a different author (Reyes \& Ariete, 2019).

Locally, in Monkayo College of Arts, Sciences, and Technology, the policy-based approach of exploring the awareness and attitude of students towards plagiarism must be established. The current Student Handbook does not reflect the rules and guidelines against cheating through plagiarism. On the other hand, the new curriculum anchored on Outcomes-Based Education reflects the academic requirements like term papers, thesis, feasibility studies, and thus requires a concrete policy from the institution related to plagiarism. Moreover, as information is readily available on the internet, the students are tempted to submit plagiarize output without proper paraphrasing and citing the source. In line with the institution's blended learning modality, it should measure the course pack's learning outcomes and assess the students' academic integrity and culture. Thus, measuring the level of sensitivity among students towards socio-cultural plagiarism detects committing this severe academic crime in the future. Generally, specific attitudes toward plagiarism can provide constructive feedback to the institution concerning establishing educational and training programs necessary to curb plagiarism. Furthermore, this feedback can help the institution to create academic codes or policies for institutional development.

\section{Theoretical Framework}

This study was anchored on the proposition of Husain, Al-shaibani, Mahfoodh, \& Ali (2017) on the combination of personal and social elements afflicting plagiarism. Supported by the theory of $\underline{\operatorname{Oghabi}}$, Pourdana, \& Ghaemi (2020), it presents plagiarism being perceived differently in different cultures (Liu, 2005 ) and will be influenced by various socio-cultural and academic contexts. Based on the literature, students' awareness, attitude, and perception towards plagiarism are indispensable to avoid plagiarism (Babalola, 2012; Onuoha \& Ikonne, 2013). Moreover, poor time management, poor organizational skills, and lack of motivation to do research are among the personal causes of plagiarism (Carroll, 2002). In the socio-cultural theoretical perspective (Vygotsky, 1978), students view human development as a socially mediated process in which students acquire their cultural values, beliefs, and problem-solving strategies through collaborative dialogues with more knowledgeable members of society. It further stresses the fundamental role of social interaction in the development of cognition as it is strongly believed that community plays a central role in making meaning. In this study, awareness describes how the students understand the meaning of plagiarism, elucidate plagiarism to be wrong, and copying from a book without crediting the source constitutes plagiarism. It is an idea that if a student violates the plagiarism policy, he/she will be caught and face serious consequences. It is also a level of understanding that faculty were effectively catching students who plagiarize, and the college is effective at sanctioning 
students who plagiarize (Ramzan, Munir, Siddique \& Asif, 2012). For attitude, it refers to a planned behavior to predict the intention to plagiarize. It was anchored on Ajzen's theory of planned behavior (TPB), a relevant predictive model of academic dishonesty that explains behavior as a final act anticipated by logical thinking (Sankar, 2020). It describes circumstances surrounding individuals and how their behaviors are explicitly affected by their surroundings, social and cultural factors for sociocultural beliefs. It also describes the student's behavior and mental processes as shaped in part by their social or cultural contact, including race, gender, and nationality (Oghabi et al., 2020). Lastly, perception is viewed as the process of recognizing, organizing, and interpreting sensory information and one of the most important avenues for research on plagiarism (Husain et al., 2017). Research on causes of student plagiarism has identified a multitude of potential contributing factors, such as inadequate understanding of citation conventions, insufficient language competence, pressure to get a high grade, pressure to complete too many assignments within a tight timeline, pressure or fear of failing a course, perceived low risk of being caught, and light penalties (Bennett 2005; Park 2003; Song-Turner, 2008).

\section{Conceptual Framework}

Dependent Variable

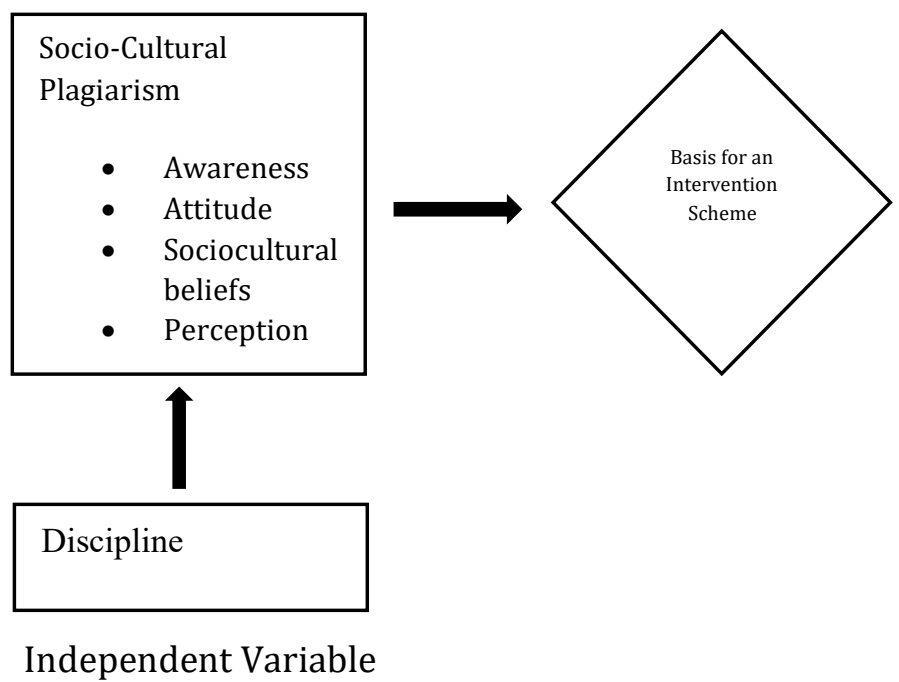

Figure 1. Conceptual framework of the study

Based on the literature and studies reviewed, this study adopted the following dimensions of socio-cultural plagiarism as depicted in Figure 1. The conceptual framework of this study centers on understanding the level of sensitivity among students towards socio-cultural plagiarism. It is instrumental in understanding the awareness, attitudes, socio-cultural beliefs, and perceptions among students as it will determine the basis for the intervention program that the institution will be implementing. Various researchers identified discipline as the most influential variable influencing sensitivity towards socio-cultural plagiarism (Rezanejad \& Rezaei, 2013; Rets \& Ali, 2018; Sankar, 2020). Although studies on university students' perceptions of plagiarism and attitudes toward plagiarism are several, most studies have examined the Western context (Husain, Al-shaibani, Mahfoodh \& Ali, 2017). Thus, the Asian, Asia-pacific, and Middle Eastern contexts have suffered a lack of studies on perceptions of plagiarism and attitudes toward plagiarism among students.

\section{Research Objectives}

This study analyzed the level of sensitivity among students towards socio-cultural plagiarism and will highlight the basis for intervention scheme in line with academic standards of Monkayo College of Arts, Sciences, and Technology. Specifically, it aimed to answer the following research objectives:

1. To determine the level of sensitivity among students towards socio-cultural plagiarism in terms of: a. awareness; 

b. attitude;
c. sociocultural beliefs;
d. perception.

2. To determine the significant difference in students' socio-cultural plagiarism levels when respondents are grouped according to discipline.

3. To determine what intervention scheme can be proposed based on the result of the study.

\section{Null Hypothesis}

Ho1 There is no significant difference in the students' level of socio-cultural plagiarism when respondents are grouped according to discipline.

\section{METHODS}

\section{Research Design}

This study used a descriptive-comparative approach. According to Creswell (2014), this design embodies a group of techniques used to research with no manipulation done to any study variable. It is primarily a quantitative research technique in which the researcher administers a survey questionnaire to a sample or an entire population of individuals to describe their attitudes, opinions, behaviors, experiences, or other characteristics. This study used an adapted Sociocultural Plagiarism Questionnaire (Oghabi, Pourdana, \& Ghaemi, 2020).

\section{Research Locale}

The study was conducted at the Monkayo College of Arts, Sciences and Technology located in Monkayo, Davao de Oro, Philippines. Monkayo College of Arts, Sciences, and Technology is one of the local colleges in the Davao Region, operated by the Local Government Unit of Monkayo under the Municipal Ordinance No. 19-2008. The Commission recognizes Higher Education institutions and a Free Tuition Law/Unifast and the Tertiary Education Subsidy, the recipient. It is also recognized as level I accredited by the Association of Local Colleges and Universities- Commission on Accreditation (ALCUCOA), and some of its major programs are now working for Level 2 accreditation. In addition, it is one of the top 30 performing schools in the Philippines during the 2019 Licensure Examination for Teachers for both the elementary and secondary level by the Professional Regulation Commission (PRC). For the Academic Year 2020-2021, the total population of the local college is 2,151. Figure 2 showing the research locale of the study.

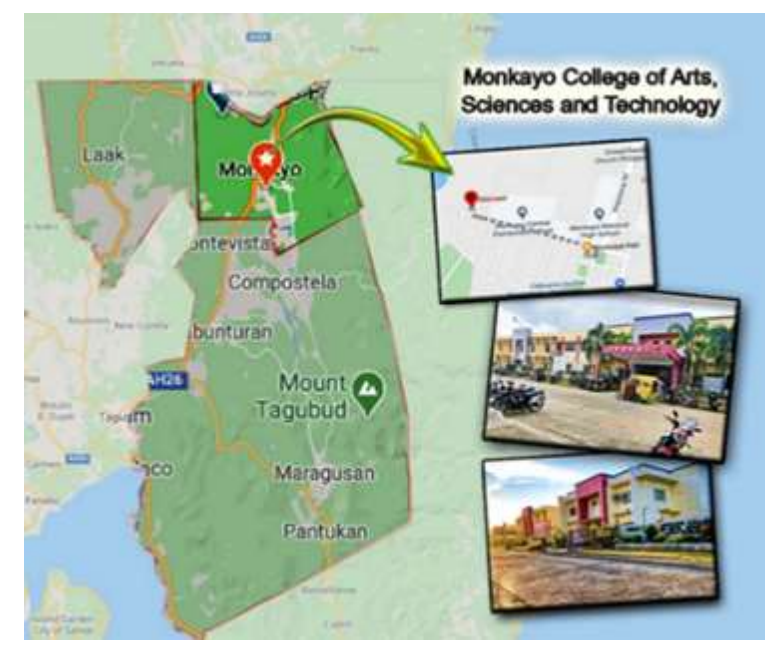

\section{Respondents of the Study}

Figure 2. Research Locale

The researchers distributed an adapted survey questionnaire to 327 respondents (plus 20\% nonresponse rate) across all degree programs in Monkayo College of Arts, Sciences, and Technology. These degree programs are; Teacher Education (with BSED-Social Studies, BSED-English, BSED-Mathematics, BEED), Bachelor of Science in Business Administration (major in Marketing, Financial \& Human 
Resource Management) Bachelor of Agricultural Technology. Samples of respondents were drawn based on the population of each department randomly.

\section{Sampling Techniques}

Simple Random Sampling was utilized in determining the respondents of this study. Identifying a population of interest and developing a systematic way of selecting cases was not based on advanced knowledge of how the outcomes would appear but to increase credibility and not foster representativeness based on the population. Hence, this study used the population of the students for the First Semester of the Academic Year of 2020-2021. Regardless of the population in each department and course, this study utilizes general response as a basis for statistical analysis. The researcher utilized Slovin's (1960) sampling formula, applied in large populations to generate a representative sample size. This sampling formula was employed mainly by determining a sample from 2,151 students in Monkayo College of Arts, Sciences, and Technology.

\section{Statistical Treatments}

In presenting, interpreting, and analyzing the data gathered, various statistical tools and techniques were used. Statistical Package for Social Sciences (SPSS) version 23 was utilized in the analysis of the data. Grouped mean score comparisons were made across the respondent's profile attribute (discipline) using Analysis of Variance (ANOVA).

\section{Data Collection Procedure}

The respondents were selected to participate in an adapted survey questionnaire where they were asked to provide answers in the most precise and insightful manner possible. The respondents were randomly selected in each department of this institution. The survey took two days to complete and collect all the required data, and the researchers utilized google forms. There was a minimum of 3 enumerators who assisted in the conduct of the study. Enumerators undergone an orientation on the purpose of the study, random sampling distribution, the number of respondents required in each specific department, the items of the questionnaire, and the consistency of the data collection method. A 6-point Likert scale was utilized to determine the level of socio-cultural plagiarism among the students and was analyzed comparatively to the independent variable (discipline). The dimensions of sociocultural plagiarism were assessed and evaluated using the Likert Scale as follows (Table 1):

Table 1. Description of Rating Scale Used for the Survey Questionnaire Tool

\begin{tabular}{|c|c|c|c|c|}
\hline $\begin{array}{l}\text { Rating } \\
\text { Scale }\end{array}$ & $\begin{array}{l}\text { Mean } \\
\text { Score } \\
\text { Range } \\
\text { Interval }\end{array}$ & $\begin{array}{l}\text { Response } \\
\text { Anchor }\end{array}$ & $\begin{array}{l}\text { Descriptive } \\
\text { Level }\end{array}$ & Interpretation \\
\hline 6 & $\begin{array}{l}5.20 \text { to } \\
6.00\end{array}$ & $\begin{array}{l}\text { Strongly } \\
\text { Agree }\end{array}$ & Extremely High & $\begin{array}{l}\text { It implies that the students are highly } \\
\text { influenced by sensitivity towards socio- } \\
\text { cultural plagiarism }\end{array}$ \\
\hline 5 & $\begin{array}{l}4.36 \text { to } \\
5.19\end{array}$ & Agree & Very High & $\begin{array}{l}\text { It implies that the students are highly } \\
\text { influenced by sensitivity towards socio- } \\
\text { cultural plagiarism }\end{array}$ \\
\hline 4 & $\begin{array}{l}3.52 \text { to } \\
4.35\end{array}$ & $\begin{array}{l}\text { Somewhat } \\
\text { Agree }\end{array}$ & High & $\begin{array}{l}\text { It implies that the students are moderately } \\
\text { influenced by sensitivity towards socio- } \\
\text { cultural plagiarism }\end{array}$ \\
\hline 3 & $\begin{array}{c}2.68 \text { to } \\
3.51\end{array}$ & $\begin{array}{l}\text { Somewhat } \\
\text { Disagree }\end{array}$ & Low & $\begin{array}{l}\text { It implies that the students are somewhat } \\
\text { influenced by sensitivity towards socio- } \\
\text { cultural plagiarism }\end{array}$ \\
\hline 2 & $\begin{array}{c}1.84 \text { to } \\
2.67\end{array}$ & Disagree & Very Low & $\begin{array}{l}\text { It implies that the students are slightly } \\
\text { influenced by sensitivity towards socio- } \\
\text { cultural plagiarism }\end{array}$ \\
\hline
\end{tabular}




$\begin{array}{cccc}1.00 \text { to } & \text { Strongly } & \text { Extremely Low } \\ 1.83 & \text { Disagree } & \end{array}$

It implies that the students are not at all influenced by sensitivity towards sociocultural plagiarism

\section{Ethical Considerations}

The research study complied with the standards set by the Monkayo College of Arts, Sciences, and Technology's Guidelines for Ethics in Research. The researcher strictly adhered to reaching the maximum level of ethical action or consideration in the scientific approach of research. Research ethics involved with requirements on actual data gathering, the protection of the respondents, and the publication of the information were in adherence to the guidelines set by the college. The compliance with these guidelines assured the respondents' rights, dignity, safety, and welfare. It also guaranteed the credibility of the research results and the ethical principles of beneficence, justice, and autonomy. Hence, the researcher adhered to the full compliance to conducting institutional research and corresponding ethical review following the study protocol assessments and standardized criteria. It was with the highest sense of responsibility that the researcher complied with the requirements of the ethical standards not limited to:

1. Voluntary participation. All respondents were given the free will to participate without any form of force or intimidation. The respondents were carefully considered and adhered to the purpose and benefits of the study voluntarily.

2. Respect for anonymity and confidentiality. The confidentiality and anonymity of all respondents were strictly adhered to in this research. The rights of beneficence, respect for dignity, and fidelity were of utmost consideration in the conduct of this study. The researcher assumed complete management of private information in order to protect the respondents' identity.

3. Informed consent process. Respondents offered their approval in this research knowingly, willingly, and intelligently, and in a clear and manifested manner. Free and informed consent needed in this study incorporates an introduction to the study. Also, its purpose and an explanation about the selection of the research respondents and the procedures followed. The questionnaire produced by the researcher was free of complicated terms and was readily understood by the research respondents. It offered a clear perspective of the researcher's advantages to the general public and the Monkayo College of Arts, Sciences, and Technology after conducting the research. The questionnaires were administered with the college authority's approval and support. Therefore, no study questionnaire was provided without authorization from the authorities that the vital elements of the informed consent process administered clear disclosure, understanding, competency, and voluntariness of respondents.

4. Risks. The research was no intention of difficult circumstances on physical, psychological, or socioeconomic implications among the respondents during this study.

\section{RESULTS}

\section{Results on the Level of Sensitivity Towards Socio-cultural Plagiarism among Students}

Table 2 shows the level of sensitivity towards socio-cultural plagiarism among students regarding awareness, attitude, socio-cultural beliefs, and perception. Results show that the level of awareness, attitude, socio-cultural beliefs, and perception towards plagiarism is low among students with awareness (mean of 2.85), attitude (mean of 2.86), socio-cultural beliefs (mean of 2.98), and perception (mean of 2.94). The overall mean is 2.92, with a descriptive equivalent of low. It implies that the students are somewhat influenced by sensitivity towards socio-cultural plagiarism in Monkayo College of Arts, Sciences, and Technology.

Table 2. Level of Sensitivity Among Students Towards Sociocultural Plagiarism

\begin{tabular}{lccc}
\hline \multicolumn{1}{c}{$\begin{array}{c}\text { Sociocultural Plagiarism } \\
\text { Dimensions }\end{array}$} & Sample Size & Mean Value & $\begin{array}{c}\text { Standard } \\
\text { Deviation }\end{array}$ \\
\hline Awareness & 350 & 2.85 & .244 \\
Attitude & 350 & 2.86 & .328
\end{tabular}




\begin{tabular}{lccc}
\hline $\begin{array}{c}\text { Sociocultural Plagiarism } \\
\text { Dimensions }\end{array}$ & Sample Size & Mean Value & $\begin{array}{c}\text { Standard } \\
\text { Deviation }\end{array}$ \\
\hline Sociocultural beliefs & 350 & 2.98 & .566 \\
Perception & 350 & 2.94 & .703 \\
Over-all Mean & 350 & 2.92 & .290 \\
\hline
\end{tabular}

Test of Significant Difference on the Level of Sociocultural Plagiarism when respondents are grouped according to discipline.

Presented in Table 3 is the ANOVA summary of significant differences in the level of sensitivity towards socio-cultural plagiarism when respondents are grouped according to discipline. As shown on the p-value of .046, it significantly differed in socio-cultural plagiarism among students when grouped according to discipline.

Table 3. Test of Significant Difference on the Respondents' Level of Sociocultural Plagiarism when respondents are grouped according to discipline

\begin{tabular}{cccccc}
\hline $\begin{array}{c}\text { Hypothesized } \\
\text { Relationship }\end{array}$ & $\begin{array}{c}\text { Sum of } \\
\text { Squares }\end{array}$ & df & Mean Square & F & Sig. \\
\hline $\begin{array}{c}\text { Between } \\
\text { Groups }\end{array}$ & .516 & 2 & .258 & 3.102 & .046 \\
Within Groups & 28.841 & 347 & .083 & & \\
\hline Total & $\mathbf{2 9 . 3 5 7}$ & $\mathbf{3 4 9}$ & & & \\
\hline
\end{tabular}

Since Anova shows a significant result, there is a need to prove this difference in pairs using a post hoc test. However, based on the Test of Homogeneity of Variance (Table 4), the Sig. is lower than the desired alpha (.05); thus, equal variance not assumed will be considered.

Table 4. Test of Homogeneity of Variance

\begin{tabular}{cccc}
\hline Levene Statistics & df1 & df2 & Sig. \\
\hline 8.846 & $\mathbf{2}$ & $\mathbf{3 4 7}$ & $\mathbf{. 0 0 0}$ \\
\hline
\end{tabular}

Therefore, the table results above with a p-value of .000 indicate the equal variance not assumed. Hence, from the two chosen tests of (Tukey HSD and Tamhane, the results of Tamhane will be considered instead of Tukey (see Table 5).

Table 5. Post Hoc Test

\begin{tabular}{|c|c|c|c|c|c|c|c|}
\hline \multirow{2}{*}{$\begin{array}{c}\text { Hypothesized } \\
\text { Relationship } \\
\text { Based on } \\
\text { Multiple } \\
\text { Comparison } \\
\end{array}$} & \multirow[t]{2}{*}{$\begin{array}{l}\text { (I)Degree } \\
\text { Programs }\end{array}$} & \multirow[t]{2}{*}{$\begin{array}{l}\text { (J)Degree } \\
\text { Programs }\end{array}$} & \multirow{2}{*}{$\begin{array}{c}\text { Mean } \\
\text { Difference } \\
\text { (I-J) }\end{array}$} & \multirow[t]{2}{*}{ Std. Error } & \multirow[t]{2}{*}{ Sig. } & \multicolumn{2}{|c|}{$\begin{array}{c}\text { 95\% Confidence } \\
\text { Interval }\end{array}$} \\
\hline & & & & & & $\begin{array}{l}\text { Lower } \\
\text { Bound }\end{array}$ & $\begin{array}{l}\text { Upper } \\
\text { Bound }\end{array}$ \\
\hline \multirow{7}{*}{ Tukey HSD } & BSBA & Teacher & - & .03530934 & .070 & - & - \\
\hline & & Education & .07828125 & & .219 & .1613929 & .00448304 \\
\hline & & BAT & - & & & - & .0312029 \\
\hline & & & .07609375 & & & .1833904 & \\
\hline & Teacher & BSBA & .07828125 & .03530934 & .070 & - & .1613929 \\
\hline & Education & BAT & .00218750 & .04993495 & .999 & $\begin{array}{l}.0048304 \\
- \\
.1153501\end{array}$ & .1197251 \\
\hline & BAT & BSBA & .07609375 & $\begin{array}{l}.04558416 \\
.04993495\end{array}$ & $\begin{array}{l}.219 \\
.999\end{array}$ & $\begin{array}{l}- \\
0312029\end{array}$ & $\begin{array}{l}.1833904 \\
.1153501\end{array}$ \\
\hline
\end{tabular}




\begin{tabular}{|c|c|c|c|c|c|c|c|}
\hline \multirow{2}{*}{$\begin{array}{c}\text { Hypothesized } \\
\text { Relationship } \\
\text { Based on } \\
\text { Multiple } \\
\text { Comparison }\end{array}$} & \multirow[t]{2}{*}{$\begin{array}{l}\text { (I)Degree } \\
\text { Programs }\end{array}$} & \multirow[t]{2}{*}{$\begin{array}{l}\text { (J)Degree } \\
\text { Programs }\end{array}$} & \multirow{2}{*}{$\begin{array}{c}\text { Mean } \\
\text { Difference } \\
(I-J)\end{array}$} & \multirow[t]{2}{*}{ Std. Error } & \multirow[t]{2}{*}{ Sig. } & \multicolumn{2}{|c|}{$\begin{array}{c}\text { 95\% Confidence } \\
\text { Interval }\end{array}$} \\
\hline & & & & & & $\begin{array}{l}\text { Lower } \\
\text { Bound }\end{array}$ & $\begin{array}{l}\text { Upper } \\
\text { Bound }\end{array}$ \\
\hline \multirow{12}{*}{ Tamhane } & & Teacher & - & & & - & \\
\hline & & Education & .00218750 & & & .1197251 & \\
\hline & BSBA & Teacher & - & .03307682 & .056 & - & .0014109 \\
\hline & & $\begin{array}{l}\text { Education } \\
\text { BAT }\end{array}$ & $\begin{array}{r}.07828125 \\
-\end{array}$ & .06009218 & .508 & .1579734 & .0715529 \\
\hline & & & .07609375 & & & .2237404 & \\
\hline & Teacher & BSBA & .07828185 & .03307682 & .056 & - & .1579734 \\
\hline & Education & BAT & .00218750 & .06354159 & 1.000 & 0014109 & .1574956 \\
\hline & & & & & & $\begin{array}{l}- \\
.1531206\end{array}$ & \\
\hline & BAT & BSBA & .07609375 & .06009218 & .508 & - & .2237404 \\
\hline & & Teacher & - & .06354159 & 1.000 & .0715529 & .1531206 \\
\hline & & Education & .00218750 & & & & \\
\hline & & & & & & .1574956 & \\
\hline
\end{tabular}

The Sociocultural Plagiarism of BSBA is not significantly different from Teacher Education (pvalue of .056); the BSBA is not significantly different from BAT (p-value of .508), and Teacher Education is not significantly different from BAT ( $p$-value of 1.000). Thus, the null hypothesis of no significant difference in socio-cultural plagiarism:

1. Between BSBA and Teacher Education is not rejected (or accepted).

2. Between BSBA and BAT is not rejected (or accepted).

3. Between Teacher Education and BAT is not rejected (or accepted).

In summary, the result reveals that the level of socio-cultural plagiarism among the students provides no significant differences in respondents' responses in terms of discipline. Therefore, the decision is to accept the null hypothesis (Ho1) that there is no significant difference in the level of sociocultural plagiarism when respondents are grouped according to discipline concerning Research Objective 2.

\section{DISCUSSION}

The research investigates the sensitivity among college students in the socio-cultural aspect of plagiarism and describes its difference according to the discipline. The research shows that the level of sensitivity among college students towards socio-cultural plagiarism is low, consistent with prior studies of Oghabi, Pourdana, \& Ghaemi, 2020; Kumar \& Mohindra, 2019; Sprajc, Urh, Jerebic, Trivan \& Łereb, 2017). Due to lack of awareness, attitude, socio-cultural beliefs, and perception, plagiarism by college students are expected, and the several reasons are due to access to digital sources, lack of understanding of plagiarism, to secure better score, to save time, negative attitude towards assignments, little or no punishment if they plagiarise, lack of academic writing skills, poor referencing skills, among others. Therefore, plagiarism performs to be more frequent among the academic community, and the acute awareness of students about the seriousness of this practice is essential ( $\underline{\text { Sankar, 2020). }}$.

The result of the study further shows that there is no significant difference in the level of sensitivity towards socio-cultural plagiarism when respondents are grouped according to discipline (business administration, teacher education, and agricultural technology). It is worth mentioning that the previous studies of Sprajc et al. (2017) highlighted the access to information and communication technology would primarily responsible for plagiarism in two aspects; the ease of copying and ease of access to materials and new technologies among students regardless of discipline. However, the data on discipline differences towards sensitivity about socio-cultural plagiarism remain inconclusive. Thus, regardless of the discipline, this aspect of research suggested that the universities and colleges must teach students about ethical concerns of plagiarism and how to avoid it. 
Moreover, the study proposed an intervention scheme as the basis for policy development anchored on existing institutional guidelines. As the basis for the intervention scheme, this study highlights the institution's five essential components: the student handbook, research manual; syllabus; technology and learning resources, and training and seminars. Kumar and Mohindra (2019) stressed that university or college officials should organize training and seminars on how to develop academic writing skills, how to avoid different types of plagiarism, how to use plagiarism detector software, how to interpret report generated by plagiarism detector software, institutional policies and ethical standards of academic writing. Generally, the attitude of respondents to strategies for curbing plagiarism favored corrective measures over punitive measures (Sankar, 2020). Hence, this aspect of the study concluded that school officials should pay close attention to this problem by developing strategies that can help resolve plagiarism in the long run. In the context of this research, table 6 presents the Re-Entry Plan and Intervention Program.

Proposed Intervention Scheme

Table 6. Re-Entry Plan and Intervention Program

\begin{tabular}{|c|c|c|}
\hline Strategic Priority & Activities & Responsible Persons \\
\hline $\begin{array}{l}\text { Student } \\
\text { Handbook }\end{array}$ & $\begin{array}{l}\text { Consultative Meeting on the Inclusion of } \\
\text { Plagiarism as part of cheating in the Rules } \\
\text { and Regulations on Conduct and } \\
\text { Discipline }\end{array}$ & $\begin{array}{l}\text { OSS Head } \\
\text { Program Heads } \\
\text { Representation from the } \\
\text { Students } \\
\text { Academic Writing Experts } \\
\text { (External) } \\
\text { Faculty Members }\end{array}$ \\
\hline Research Manual & $\begin{array}{l}\text { Review of the Provisions of Ethics and } \\
\text { Review in the Research Manual }\end{array}$ & Academic Council \\
\hline Syllabus & $\begin{array}{l}\text { Review of the Syllabus on the Inclusion of } \\
\text { Plagiarism as a Serious Offense }\end{array}$ & $\begin{array}{l}\text { Members of the Academic } \\
\text { Council } \\
\text { Program Heads } \\
\text { Quality Assurance Officer }\end{array}$ \\
\hline $\begin{array}{l}\text { Technology and } \\
\text { Learning Resources }\end{array}$ & $\begin{array}{l}\text { Consultative Meeting with the Library } \\
\text { Committee on the Utilization of Turnitin } \\
\text { (plagiarism software) and the use of } \\
\text { Grammarly (as a paraphrasing tool). }\end{array}$ & $\begin{array}{l}\text { Members of the Library } \\
\text { Committee }\end{array}$ \\
\hline Training and Seminars & $\begin{array}{l}\text { Conduct Plagiarism Awareness Seminar } \\
\text { and Writing Sessions on the following: } \\
\text { 1. Word-for Word Copying (verbatim) } \\
\text { 2. Paraphrasing (Mosaic Plagiarism, } \\
\text { Sham Paraphrasing, Inadequate } \\
\text { Paraphrasing, Illicit Paraphrasing) } \\
\text { 3. illicit Referencing } \\
\text { 4. Intentionality (Intentional Plagiarism, } \\
\text { Cryptomnesia, } \\
\text { 5. Peer Plagiarism (Purloining, Ghost } \\
\text { Writing, Recycling) } \\
\text { 6. Internet Plagiarism }\end{array}$ & $\begin{array}{l}\text { Academic Program Heads } \\
\text { Faculty Teaching } \\
\text { Academic Writing } \\
\text { External Expert }\end{array}$ \\
\hline
\end{tabular}




\section{CONCLUSION}

It is essential to mention that the main objective of this study was to measure the sensitivity among students towards plagiarism in terms of awareness, attitudes, socio-cultural beliefs, and perceptions. Furthermore, highlighting the sensitivity among students towards plagiarism can be addressed by Monkayo College of Arts, Sciences, and Technology by creating strategies that can be employed to reduce plagiarism or curb it in the academic culture through an intervention scheme. Based on the results and interpretation of the study, the following conclusions have been generated:

1. 1.The level of sensitivity among students towards socio-cultural plagiarism is low. Therefore, it concludes that the students are somewhat influenced by sensitivity towards socio-cultural plagiarism in Monkayo College of Arts, Sciences, and Technology.

2. 2.The result revealed that the level of sensitivity among students towards socio-cultural plagiarism provides no significant differences in respondents' responses in terms of discipline. It concludes that regardless of the discipline (Business Administration, Teacher Education, and Agricultural Technology), the sensitivity among students towards socio-cultural plagiarism does not differ. However, exciting challenges is being observed in MonCAST where students from different discipline share an everyday awareness, attitudes, perceptions and socio-cultural beliefs towards a culture of plagiarism and the less regard of ethical considerations in this aspect.

3. 3.The basis for the intervention scheme must be anchored to the conduct and discipline of the institution related to the student handbook, research manual, and integration of academic policies in the syllabus against plagiarism, investing technology and learning resources, and training and seminars. Academic orientation should also highlight the awareness of the academic community towards committing this academic crime. Moreover, the academic integrity policy must be addressed entirely based on the academic culture and interpret entirely based on institutional policies.

\section{Recommendations}

Based on the detailed and significant evaluation of results, the researcher recommends the following:

1. To Monkayo College of Arts, Sciences, and Technology. This study suggests that the institution should integrate plagiarism as cheating under the Rules and Regulations on Conduct and Discipline. The Student Handbook should emphasize the disciplinary action on the offense with corresponding penalties as a form of cheating or academic dishonesty. In addition, the institution should conduct an awareness program related to plagiarism. It is also high time for the institution to invest in paraphrasing tools like Grammarly and anti-plagiarism software like Turnitin. Faculty members should also recognize their responsibility to prevent plagiarism, such as setting up a clear-cut class policy toward plagiarism and structuring meaningful assignments to guide students to behave ethically.

2. To the Commission on Higher Education. Review existing guidelines and policies on plagiarism and implement rules against dishonesty and cheating in school. The policy should also review the offense of grave misconduct as to punishable by suspension, dismissal, and dropping off the rolls imposed by colleges and universities.

3. To the Academicians. The study suggests that academicians include socio-cultural plagiarism as a topic in Professional Education Subjects. In addition, the cases or literature can be a source of Special Topics in the Module.

4. To Future Researchers. To conduct studies related to socio-cultural plagiarism and the students' academic performance. It is also essential to identify the factors contributing to plagiarism, as the abundance of information technology and electronic resources for educational materials, as there is no exact taxonomy that can account for all these factors. Future researchers may need to consider focusing on factors explaining plagiarism, as few researchers presented a comprehensive taxonomy about it. Moreover, the research has limitations that may provide scopes for sex differences in a more extensive scope (regional or provincial), other colleges and universities, and other disciplines like criminology, medicine, arts, and sciences. 


\section{Funding and Conflicts of Interest:}

The authors declare that there is no funding and conflicts of interest for this research.

\section{REFERENCES}

Altbach, P. (2004). The Question of Corruption. International Higher Education, (34). https://doi.org/10.6017/ihe.2004.34.7399

Babalola, Y. (2012). Awareness and incidence of plagiarism among undergraduates in a Nigerian private university. African Journal of Library, Archives and Information Science, 22(1), 53-61. Retrieved from https://www.ajol.info/index.php/ajlais/article/view/106585

Bennett, R. (2005). Factors associated with student plagiarism in a post-1992 university. Assessment \&Evaluation in Higher Education, 30, 137162. Retrieved from https://www.tandfonline.com/doi/abs/10.1080/0260293042000264244

Carroll, J. (2002). A handbook for deterring plagiarism in higher education. Oxford: Oxford Centre for Staff and Learning Development. Retrieved from https://www.beds.ac.uk/jpd/volume-4issue-1/a-handbook-for-deterring-plagiarism-in-higher-education/

Creswell, J.W. (2014). Research design: qualitative, quantitative and mixed methods approaches (4th ed.). Thousand Oaks, CA: Sage. Retrieved from https://www.scirp.org/(S(i43dyn45teexjx455qlt3d2q))/reference/ReferencesPapers.aspx?R eferenceID $=1964849$

Husain, F. M., Al-shaibani, G., Mahfoodh, O. H., \& Ali. (2017). Perceptions of and attitudes toward plagiarism and factors contributing to plagiarism: A review of studies. Journal of Academic Ethics, 15(2), 167-195. DOI: http://dx.doi.org/10.1007/s10805-017-9274-1

Kumar, A., \& Mohindra, R. (2019). Exploring awareness and attitude on plagiarism among research scholars: A case study of Panjab university, Chandigarh (india). Library Philosophy and Practice, , 1-14. Retrieved from https://www.proquest.com/scholarly-journals/exploringawareness-attitude-on-plagiarism-among/docview/2234440333/se-2?accountid=31259

Oghabi, M., Pourdana, N., Ghaemi, F. (2020). Developing and Validating a Socio-cultural Plagiarism Questionnaire for Assessing English Academic Writing of Iranian Scholars. Applied Research on English Language, 9(2), 277-302. DOI: http://dx.doi.org/10.22108/are.2019.118587.1485

Onuoha, U., \& Ikonne, C. (2013). Dealing with the plague of plagiarism in Nigeria. Journal of Education and Practice, 4(11), 102-106. Retrieved from https://core.ac.uk/download/pdf/234634388.pdf

Park, C. (2003). In other (people's) words: plagiarism by university studentsliterature and lessons. Assessment \& Evaluation in Higher Education, 28(5), 471488. Retrieved from https://www.tandfonline.com/doi/abs/10.1080/02602930301677

Rets, I., \& Ali, I. (2018). Eliciting ELT students' understanding of plagiarism in academic writing. Eurasian Journal of Applied Linguistics, 4(2), 193-211. Retrieved from https://www.proquest.com/docview/2264295325?accountid=31259

Reyes, M. P. P., \& Ariate, J. F. (2019). Internal affairs: The fate of authors from the University of the Philippines accused of plagiarism, 1990s to 2010s. Sci Ed, 6(2), 128-136. https://doi.org/10.6087/kcse.173

Rezanejad, A., \& Rezaei, S. (2013). Academic dishonesty at universities: The case of plagiarism among iranian language students. Journal of Academic Ethics, 11(4), 275-295. doi: http://dx.doi.org/10.1007/s10805-013-9193-8 
Sankar, P. (2020). Measuring The Attitude Towards Plagiarism: A Study. Library Philosophy and Practice, 1-20. Retrieved from https://www.proquest.com/docview/2446728152?accountid=31259

Slovin's Formula Sampling Techniques. (n.d.). Sciencing. Retrieved May 30, 2021, from https://sciencing.com/slovins-formula-sampling-techniques-5475547.html

Song-Turner, H. (2008). Plagiarism: Academic dishonesty or blind spot of multicultural education?Australian Universities Review, 50, 3950. Retrieved from https://files.eric.ed.gov/fulltext/EJ824687.pdf

Sprajc, P., Urh, M., Jerebic, J., Trivan, D., \& Jereb, E. (2017). Reasons for plagiarism in higher education. Organizacija, 50(1), 33-45. doi: http://dx.doi.org/10.1515/orga-2017-0002

Survey reveals most serious, common types of plagiarism in research: 10 types of plagiarism and attribution issues decoded and displayed in interactive chart. (2013, Oct 08). PR Newswire Retrieved from https://www.proquest.com/docview/1440028784?accountid=31259

Sutherland-Smith, W. (2008). Plagiarism, the Internet, and student learning: improving academic integrity: Routledge. Retrieved from https://www.routledge.com/Plagiarism-the-Internetand-Student-Learning-Improving-Academic-Integrity/SutherlandSmith/p/book/9780415432931

Vygotsky, L. S. (1978). Mind in society: The development of higher psychological processes. Cambridge, MA: Harvard University Press. Retrieved from https://www.jstor.org/stable/j.ctvjf9vz4

Yeo, S. (2007). First-year university science and engineering students understanding of plagiarism. High Education Research \& Development, 26(2), 199216. Retrieved from https://www.tandfonline.com/doi/abs/10.1080/07294360701310813 